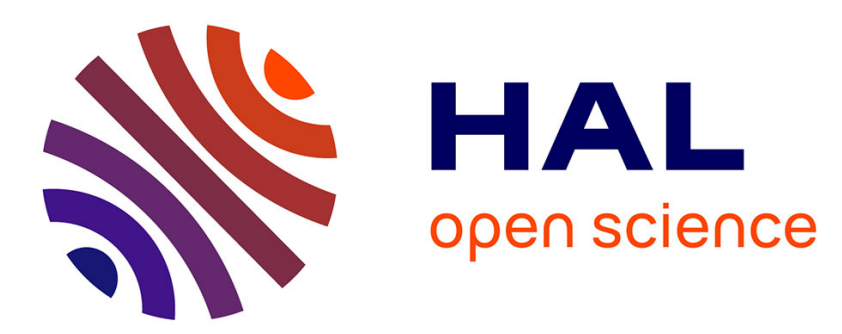

\title{
Mechanical properties of bulk polydimethylsiloxane for microfluidics over a large range of frequencies and aging times
}

Vincent Placet, Patrick Delobelle

\section{- To cite this version:}

Vincent Placet, Patrick Delobelle. Mechanical properties of bulk polydimethylsiloxane for microfluidics over a large range of frequencies and aging times. Journal of Micromechanics and Microengineering, 2015, 25 (3), pp.035009. hal-02946409

\section{HAL Id: hal-02946409 \\ https://hal.science/hal-02946409}

Submitted on 23 Sep 2020

HAL is a multi-disciplinary open access archive for the deposit and dissemination of scientific research documents, whether they are published or not. The documents may come from teaching and research institutions in France or abroad, or from public or private research centers.
L'archive ouverte pluridisciplinaire HAL, est destinée au dépôt et à la diffusion de documents scientifiques de niveau recherche, publiés ou non, émanant des établissements d'enseignement et de recherche français ou étrangers, des laboratoires publics ou privés. 


\title{
Mechanical properties of bulk polydimethylsiloxane for microfluidics over a large range of frequencies and aging times
}

\author{
V Placet and P Delobelle \\ FEMTO-ST, DMA (UMR CNRS 6174), Université de Franche-Comté, 24 chemin de 1'Epitaphe, \\ 25000 Besançon, France \\ E-mail: patrick.delobelle@univ-fcomte.fr
}

Received 17 October 2014, revised 17 December 2014

Accepted for publication 29 December 2014

Published

\begin{abstract}
The dynamic mechanical characterization of polydimethylsiloxane (PDMS) over a large range of frequencies $\left(10^{-2}<f<10^{5} \mathrm{~Hz}\right)$ and long aging times at room temperature $\left(4 \mathrm{~h}<t_{\mathrm{v}}<\sim 60000 \mathrm{~h}\right)$ has been presented. Three samples with different curing conditions have been studied and three different techniques, dynamic mechanical analysis at different temperatures, nano-indentation and scanning micro-deformation microscopy, have been used. Although the three techniques work at different scales and at different frequencies all the results match the same master curve. As expected, the storage and the loss moduli greatly increase with the frequency. Moreover, these moduli moderately increase with the aging time $t_{\mathrm{V}}$ depending on the curing temperature. A simple model which takes the frequency and the aging time into account, and which is based on the Havriliak-Negami model, has been presented and identified. Hence, values of the relaxed and instantaneous moduli at $t_{\mathrm{v}}=0$ and $t_{\mathrm{v}}=\infty$ are proposed. Only the relaxed moduli depend on the curing conditions and moreover it has been shown that the tangent of the phase lag is independent of the aging time and thus of the curing process.
\end{abstract}

Keywords: PDMS bulk material, curing conditions, dynamic mechanical analysis, viscoelastic properties, aging

(Some figures may appear in colour only in the online journal)

\section{Introduction}

Polydimethylsiloxane (PDMS) has become the most popular building material used in a variety of low-cost aqueous microfluidic devices (values, pumps, fluidic circuits) aimed in particular at single use applications for biological or medical diagnostics [1-5]. Some applications have also been reported in micro-optical systems (micro-opto-electro-mechanical systems (MOEMS) such as adaptative lenses, tilting mirrors etc) $[6,7]$ and in microelectromechanical systems (MEMS) sensors (chemical, medical, tactile sensors etc) [8,9]. In fact its extreme ease of use combined with its good mechanical properties (high elasticity), biocompatibility and transparency underpin the widespread use of PDMS. In the microfluidic applications, in order to have low power consumption, many groups use this material for mobile parts (often membranes) in active systems such as micro-valves or micro-pumps [2-4, 10, 11]. However, there are few reported characterizations of the bulk mechanical properties of cross linked PDMS under well defined curing temperature conditions and long aging times [5, 8, 12-17]. However, a limited amount of published data is devoted to the dynamic mechanical properties $[1,5]$. Some analyzing elements of these two different points are presented in this paper. 


\section{Materials and experimental procedures}

\subsection{Material}

To realize the PDMS samples, the Sylgard 184 PDMS kit manufactured by Dow Corning Corporation [18] and composed of a prepolymer and a curing agent has been used. The prepolymer and curing agent in the ratio 10:1 were mixed with an Ultra Turax homogenizer for $30 \mathrm{~s}$. The solution was poured into a Petri dish up to a thickness of about 3-4 mm and degassed in a dessicator by the application of vacuum for $15 \mathrm{~min}$, with cycles of $2 \mathrm{~min}$ between atmospheric pressure and $0.5 \mathrm{~Pa}$. The solution was then cured in an oven at $65^{\circ} \mathrm{C}$ for $4 \mathrm{~h}$ following the recommendations from Dow Corning $[9,18]$. This procedure has been applied to a plate labelled 'Spec.1'. A second plate (labelled 'Spec.2') with a curing time of $10 \mathrm{~h}$ at $65^{\circ} \mathrm{C}$ has also been elaborated. Indeed, these two curing conditions are those encountered during the fabrication process of an active micro-valve for microfluidic applications [19], i.e. step 1: elaboration of the active membrane corresponding to Spec.1, and step 2: bounding under the load of both lower and upper parts of the micro-valve corresponding to Spec.2 [19]. Then, PDMS was demolded and cut to make rectangular specimens (thickness $\sim 3.75 \mathrm{~mm}$, width $\sim 14 \mathrm{~mm}$ and useful length $\sim 35 \mathrm{~mm}$ ). Some data obtained five years ago on a PDMS specimen cured at $180^{\circ} \mathrm{C}$ for $30 \mathrm{~min}$ and labelled 'Spec.3' are also presented for comparison with the two precedent ones, as this curing condition gives the maximum hardening of the material $[8,15]$.

\subsection{Experimental procedures}

Specimens 1 and 2 have been characterized thanks to three different techniques (dynamic mechanical analysis (DMA), nano-indentation and scanning micro-deformation microscope (SMM) over long aging times $t_{\mathrm{v}}\left(t_{\mathrm{v}} \sim 63000 \mathrm{~h} \sim 7\right.$ years $)$ at room temperature $T \sim 20-23^{\circ} \mathrm{C}$.

For each DMA experiment the dimensions of the cross section of the tested specimen have been accurately measured with an accuracy of $\pm 0.05 \mathrm{~mm}$. The distance between the two jaws where the specimen is attached has been measured (precision wedges) with a precision of $0.1 \mathrm{~mm}$. However, due to the standard tensile specimen shape (dog bone shape), the precision of the useful length (homogeneous strain and stress) to determine the strain has been estimated to $0.5 \mathrm{~mm}$ (finite element modeling). Finally, taking the dimensions of the tested specimens and these different uncertainties into account, the precision on the modulus is in the range $3-4 \%$.

The DMA measurements with frequencies in the range of $0.01-80 \mathrm{~Hz}$ have been performed on a commercial BOSE Electroforce 3200 machine at room temperature for the three specimens and at $T=0,-20,-40$ and $-60^{\circ} \mathrm{C}$ for Spec. 1 at $t_{\mathrm{v}} \sim 4, \sim 11000$ and $\sim 56000 \mathrm{~h}$. Thus, for this last sample the time-temperature equivalence has been analyzed over a large domain of frequency: $10^{-2}<f<10^{5} \mathrm{~Hz}$. According to the ASTM Guide for Dynamic Testing, the software calculates the values of $E^{\prime}$, the storage modulus, $E^{\prime \prime}$ the loss modulus and $\tan (\delta)=E^{\prime \prime} / E^{\prime}$, the tangent of the phase angle.
Nano-indentation tests have been carried out using a NanoIndenter $\mathrm{II}^{\mathrm{S}}$ equipped with a Berkovich tip. The study was conducted following the classical method (quasi-static) and continuously with the CSM technique at a frequency of $45 \mathrm{~Hz}$ [20]. With this last method $E^{\prime}$ and $E^{\prime \prime}$ can be calculated thanks to a suitable model [21]. For each tested sample the measurement sequence consists of five indents with a maximum penetration depth of $h_{\max }=5 \mu \mathrm{m}$ and an approximately constant rate equal to $2 \times 10^{-2} \mathrm{~s}^{-1}$. For the quasi-static method five unloadings were performed at about $1,2,3,4$ and $5 \mu \mathrm{m}$ and $50 \%$ of the unloading curves are considered to calculate the contact stiffness. For the CSM procedure the indenter vibrates at $45 \mathrm{~Hz}$ with an amplitude of $2 \mathrm{~nm}$ during the indenter penetration.

Some experiments at high frequency have been performed thanks to the SMM, which is a type of ac force contact microscope $[22,23]$. The sensor is a micromechanical resonator composed of a silicon cantilever with a small sharp sapphire tip at the end. This cantilever is glued onto a piezoelectric bimorph transducer at the other end. This transducer excites the vibration of the tip-sample system. The tip remains in contact with the sample and vibrates at some $\mathrm{kHz}$ with an amplitude of some nanometers. The amplitude and phase of the cantilever vibration are measured with a high sensitivity heterodyne interferometer [22, 23]. This microscope is an effective tool to record images of surfaces or sub-surfaces with heterogeneous local elasticity or to characterize elastic properties of materials. In this study it has been used to measure the complex Young's modulus of the PDMS samples. The excitation frequency is scanned and the first resonant frequency which depends on the static force exerted by the tip onto the sample can be determined. Actually, knowing this resonant frequency and the static force, local contact stiffness can be estimated and then with a well-suited model [21, 23] the storage and the lost moduli are extracted. This has been done on the three samples at different aging times (figure 1) and with two different (but close to each other) cantilevers. So the resonant frequencies are slightly different and in the range $2.6-4.5 \mathrm{kHz}$.

\section{Results and analysis}

\section{1. $E^{\prime}$ and $E^{\prime \prime}$ moduli as a function of the frequency}

Figures $1(a)$ and $(b)$ give for Spec. 1 and three aging times $\left(t_{\mathrm{v}}=4,11000\right.$ and $\left.56000 \mathrm{~h}\right)$ the evolutions of $E^{\prime}$ and $E^{\prime \prime}$, determined with the three experimental techniques, as a function of the excitation frequency. For this material we took $\nu=0.48$ for the Poisson's ratio. The William-Landel-Ferry (WLF) model has been applied to calculate the storage and loss moduli master curve (DMA analysis) is shown in figures $1(a)$ and $(b)$. In this model, for a fixed reference temperature $T_{0}$, the translation parameter $a_{\mathrm{T} / \mathrm{To}}$ of the frequencies is given by:

$$
\begin{aligned}
& E^{(j)}(T, f)=E^{(j)}\left(T_{0}, a_{\mathrm{T} / \mathrm{T}_{0}}, f\right) \text { with } \operatorname{Ln}\left(a_{\mathrm{T} / \mathrm{T}_{0}}\right)=\frac{-\mathrm{C}_{1}\left(T-T_{0}\right)}{\mathrm{C}_{2}+T-T_{0}} \\
& \quad \text { and }(j)=\left({ }^{\prime} \text { or " }\right) .
\end{aligned}
$$



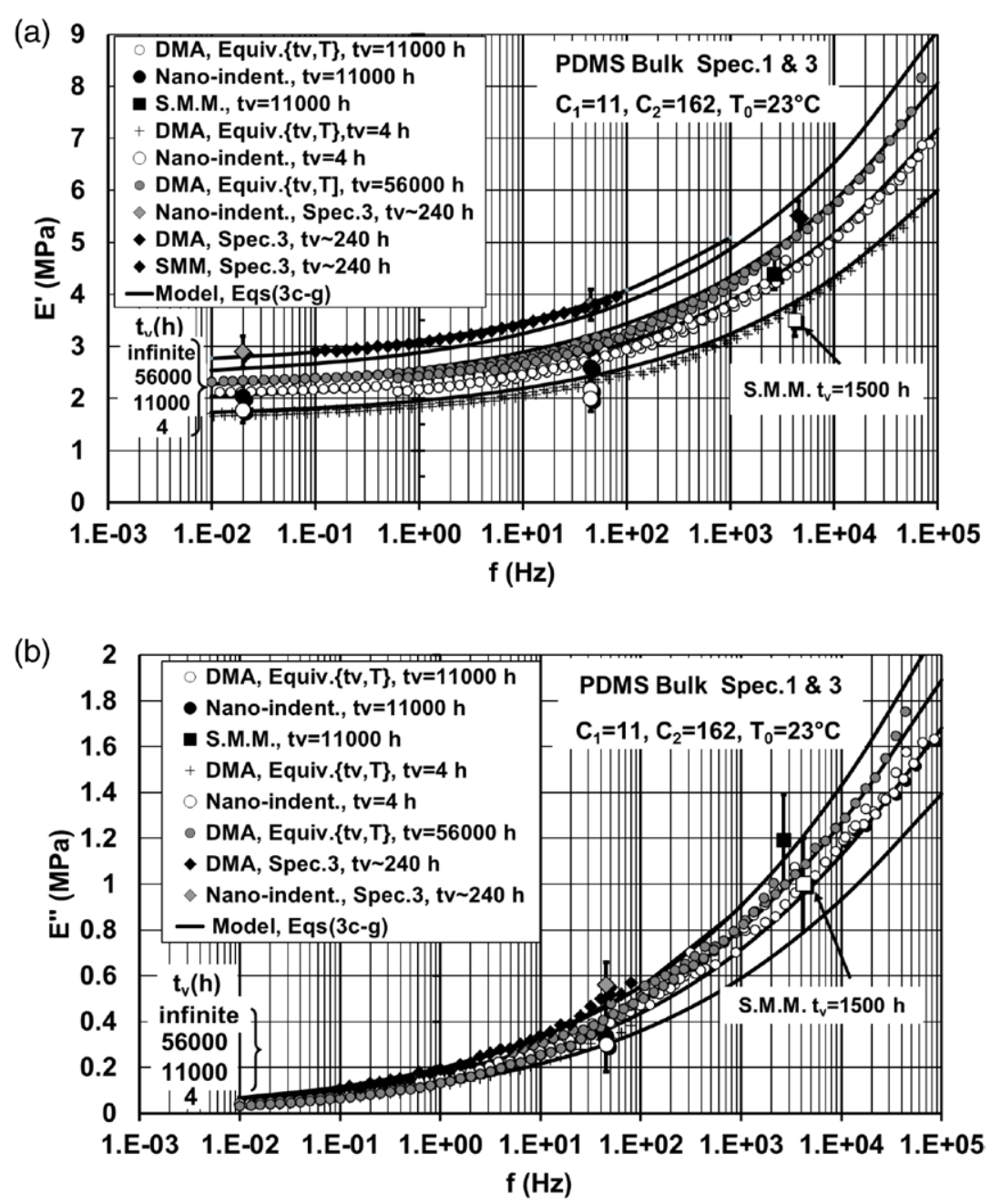

Figure 1. (a): Storage modulus (Spec.1 and Spec.3) determined with the three techniques as a function of the frequency and the aging time. The four lower solid lines correspond to the model response (equations (3c)-(3g)) for Spec. 1 at $t_{\mathrm{v}}=4,11000,56000 \mathrm{~h}$ and for an infinite time. The upper solid curve is the model response for Spec. 3 at $t_{\mathrm{v}}=240 \mathrm{~h}$. (b): Loss modulus (Spec.1 and Spec.3) determined with the three techniques as a function of the frequency and the aging time. As for $(a)$ the four lower solid lines correspond to the model response (equations (3c)-(3g)) for Spec.1 at $t_{\mathrm{v}}=4,11000,56000 \mathrm{~h}$ and for an infinite time. The upper solid curve is the model response for Spec.3 at $t_{\mathrm{v}}=240 \mathrm{~h}$

In this relation, $T_{0}=23^{\circ} \mathrm{C}, \mathrm{C}_{1}=11$ and $\mathrm{C}_{2}=162$, whatever the time aging. $E^{\prime}$ and $E^{\prime \prime}$ increase with the frequency $\left(0.01<f<10^{5} \mathrm{~Hz}\right)$ from 2 to $7.5 \mathrm{MPa}$ and 0.02 to $1.6 \mathrm{MPa}$, respectively.

It is interesting to note that, although the three techniques work at different scales (micro and macro) and at different frequencies, nano-indentation (quasi-static and dynamic $(f=45 \mathrm{~Hz}))$ and SMM $(f \sim 3$ and $4.5 \mathrm{kHz})$ results perfectly match the master curves determined from the DMA procedure $(0.01-80 \mathrm{~Hz})$ and thus a posteriori validate the application of the WLF model to this material. Note that for these two last experimental methods the calculated uncertainties on $E^{\prime \prime}$ are fairly large. Moreover, from figures $1(a)$ and $(b)$ it is obvious that the two moduli evolve with the aging time.

\section{2. $E^{\prime}$ and $E^{\prime \prime}$ moduli as a function of the aging time}

For the two studied specimens (Spec.1 and Spec.2), figures 2(a) and $(b)$ show the variations of $E^{\prime}$ and $E^{\prime \prime}$ (DMA analysis at room temperature) with the aging time $t_{\mathrm{v}}\left(4 \mathrm{~h}<t_{\mathrm{v}}<\sim 60000 \mathrm{~h}\right)$ and for three frequencies: $0.01,1$ and $80 \mathrm{~Hz}$. Note that the first measurements have been carried out approximately $4 \mathrm{~h}$ after the fabrication of the samples. These moduli clearly increase with aging. Due to the additional curing time of Spec. $2(10 \mathrm{~h})$ the initial value of the storage modulus $E^{\prime}(4 \mathrm{~h}, 0.01 \mathrm{~Hz})=2.05 \mathrm{MPa}$ is greater than that of Spec. $1, E^{\prime}(4 \mathrm{~h}, 0.01 \mathrm{~Hz})=1.7 \mathrm{MPa}$ (figure $2(a)$ ). So, an additional curing time of $6 \mathrm{~h}$ at $65^{\circ} \mathrm{C}$ sensibly corresponds to an aging of $10000 \mathrm{~h}$ at room temperature. Otherwise, for the two specimens the initial values of $E^{\prime \prime}$ are close to each other (figure 2(b)). Moreover, Spec. 3 which has been cured at $180^{\circ} \mathrm{C}$ and tested at $t_{\mathrm{v}} \sim 256 \mathrm{~h}$ exhibits an initial value at $0.1 \mathrm{~Hz}$ equal to $2.9 \mathrm{MPa}$. These observations will be discussed further.

To quantitatively take these variations into account an Avrami's kinetic have been chosen and the following relation is proposed:

$$
\begin{aligned}
& 1-?(t)=\exp (-Z(T)) t^{n} \text { then : } \\
& E^{(j)}\left(t_{\mathrm{v}}, \omega\right)=E^{(j)}(0, \omega)+\left(E^{(j)}(\infty, \omega)-E^{(j)}(0, \omega)\right) \\
& {\left[1-\exp -\left(\frac{t_{\mathrm{v}}}{t_{0}}\right)^{n}\right] \quad \text { with } j=\left({ }^{\prime} \text { or " }\right)}
\end{aligned}
$$



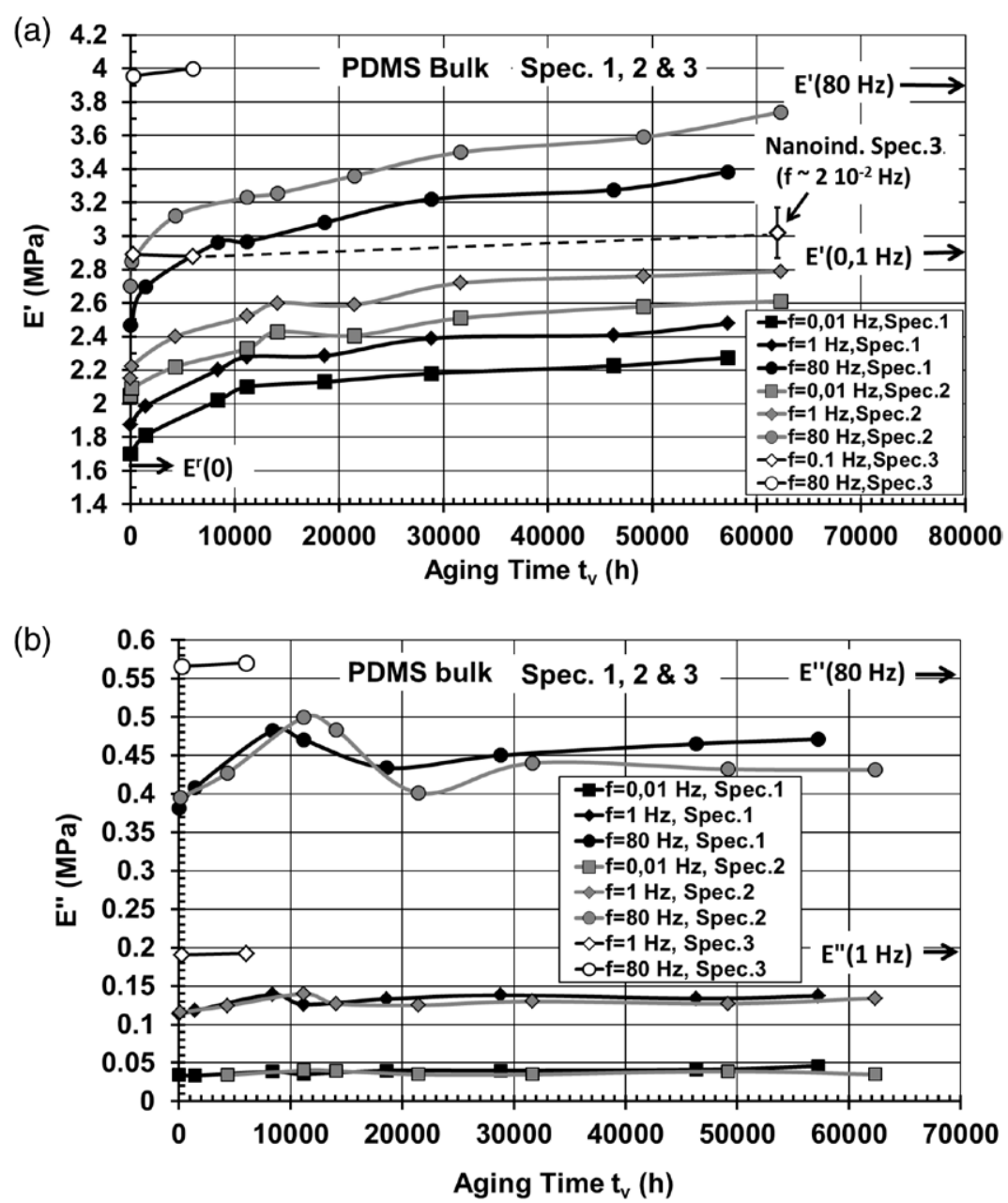

Figure 2. (a): Storage modulus (Spec.1, Spec.2 and Spec.3) as a function of the aging time. (b): Loss modulus (Spec.1, Spec.2 and Spec.3) as a function of the aging time.

$\operatorname{or} \frac{E^{(j)}\left(t_{\mathrm{v}}, \omega\right)}{E^{(j)}(0, \omega)}=1+\left(\frac{E^{(j)}(\infty, \omega)}{E^{(j)}(0, \omega)}-1\right)\left[1-\exp -\left(\frac{t_{\mathrm{v}}}{t_{0}}\right)^{n}\right]$

and $\omega=2 \pi f$

For the two studied specimens the relation $(2 b)$, $E^{\prime}\left(t_{\mathrm{v}}, \omega\right) / E^{\prime}(4 h, \omega)=f\left(t_{\mathrm{v}}\right)$ has been represented in figure 3 for three frequencies $(0.01,1$ and $80 \mathrm{~Hz})$. Note that $E^{\prime}(0, \omega) \sim$ $E^{\prime}\left(t_{\mathrm{v}}=4 \mathrm{~h}, \omega\right)$. The identified parameters corresponding to the four curves drawn in figure 3 (equation $(2 b)$ ) are: $t_{0}=46000 \mathrm{~h}$, $n=0.5, E^{\prime}(\infty, \omega) / E^{\prime}(0, \omega)=1.49$ and 1.55 (Spec. 1$)$ and 1.4 and 1.47 (Spec.2) for $f=0.01$ and $80 \mathrm{~Hz}$, respectively. The $E^{\prime}(\infty, \omega) / E^{\prime}(0, \omega)$ ratio sensibly increases with the frequency. Note that the fitting of the experimental points in figure 3 allows the two kinetic parameters $n$ and $t_{0}$ of the relation (2a) to be determined. Hence, for an infinite aging time the maximum increase of the Young's modulus values is about 50 and $40 \%$ for the specimens 1 and 2, respectively. The value $n=1 / 2$ is difficult to explain as it is not directly associated with the physical nature of the evolution of the cross-linking. As an example, for crystal growth in polymer, $n$ is in the range 1-4 depending on the nucleation and the crystallization mechanisms.

\subsection{Phenomenological modeling: frequency and time aging dependencies}

Taking the aging into account, for viscoelastic materials the general equation of the complex modulus is given by:

$$
\begin{gathered}
E^{*}\left(t_{\mathrm{v}}\right)=E^{\mathrm{i}}\left(t_{\mathrm{v}}\right)+\left(E^{\mathrm{r}}\left(t_{\mathrm{v}}\right)-E^{\mathrm{i}}\left(t_{\mathrm{v}}\right)\right) f\left(\mathrm{i} \omega \tau_{j}\right) \text { with } f\left(\mathrm{i} \omega \tau_{j}\right)= \\
\sum_{j=1}^{m} p_{j} \frac{1}{1+\mathrm{i} \omega \tau_{j}} \text { and } \sum_{j=1}^{m} p_{j}=1
\end{gathered}
$$

where $E^{\mathrm{i}}\left(t_{\mathrm{v}}\right)$ and $E^{\mathrm{r}}\left(t_{\mathrm{v}}\right)$ are the instantaneous and relaxed Young's moduli, respectively and $\tau_{j}$ a number $m$ of discrete relaxation times whose ponderation coefficients are $p_{j}$. From a phenomenological point of view and considering the Havriliak-Negami model [24], $f\left(i \omega \tau_{j}\right)$ can be written as a continuous complex function of the argument $i \omega \tau$ :

$$
f\left(\mathrm{i} \omega \tau_{j}\right)=\frac{1}{\left(1+(\mathrm{i} \omega \tau)^{\alpha}\right)^{\beta}}
$$




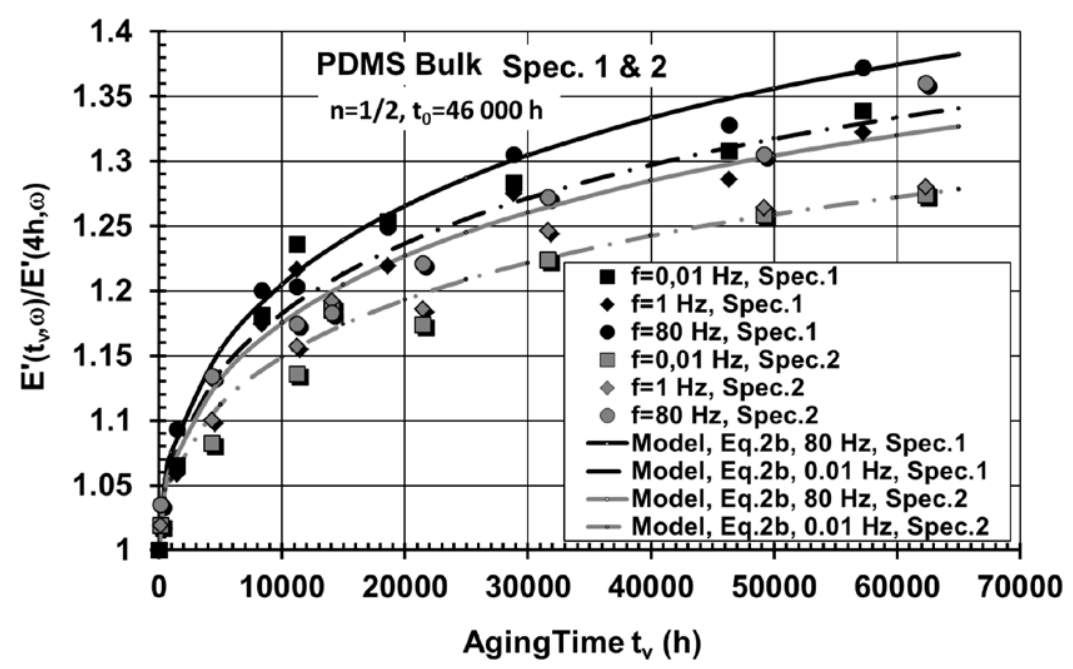

Figure 3. Aging kinetic of the storage modulus (Spec.1, Spec.2 and Spec.3). Model, equation (2b).

Hence, storage and loss moduli are given by:

$$
\begin{aligned}
& E^{\prime}\left(t_{\mathrm{v}}\right)=E^{\mathrm{i}}\left(t_{\mathrm{v}}\right)+\left(E^{\mathrm{r}}\left(t_{\mathrm{v}}\right)-E^{\mathrm{i}}\left(t_{\mathrm{v}}\right)\right) \\
& \frac{\cos (\beta \varphi)}{\left(1+2(\omega \tau)^{\alpha} \cos (\alpha \pi / 2)+(\omega \tau)^{2 \alpha}\right)^{\beta / 2}} \\
& E^{\prime \prime}\left(t_{\mathrm{v}}\right)=\left(E^{\mathrm{i}}\left(t_{\mathrm{v}}\right)-E^{\mathrm{r}}\left(t_{\mathrm{v}}\right)\right) \\
& \frac{\sin (\beta \varphi)}{\left(1+2(\omega \tau)^{\alpha} \cos (\alpha \pi / 2)+(\omega \tau)^{2 \alpha}\right)^{\beta / 2}}
\end{aligned}
$$

with

$$
\varphi=\tan ^{-1}\left(\frac{(\omega \tau)^{\alpha} \sin (\alpha \pi / 2)}{1+(\omega \tau)^{\alpha} \cos (\alpha \pi / 2)}\right)
$$

and taking equation $(2 a)$ into account:

$$
\begin{aligned}
& E^{\mathrm{i}}\left(t_{\mathrm{v}}\right)=E^{\mathrm{i}}(0)+\left(E^{\mathrm{i}}(\infty)-E^{\mathrm{i}}(0)\right)\left[1-\exp -\left(\frac{t_{\mathrm{v}}}{t_{0}}\right)^{n}\right] \\
& E^{\mathrm{r}}\left(t_{\mathrm{v}}\right)=E^{\mathrm{r}}(0)+\left(E^{\mathrm{r}}(\infty)-E^{\mathrm{r}}(0)\right)\left[1-\exp -\left(\frac{t_{\mathrm{v}}}{t_{0}}\right)^{n}\right]
\end{aligned}
$$

The model is composed of equations $(3 c)-(3 g), \tau$ is a single relaxation time, $\alpha$ and $\beta$ two empirical exponents and $E^{\mathrm{i}}(0), E^{\mathrm{r}}(0), E^{\mathrm{i}}(\infty), E^{\mathrm{r}}(\infty)$ the instantaneous $(f=\infty)$ and the relaxed $(f=0)$ modulus at $t_{\mathrm{v}}=0$ and $\infty$, respectively. As previously shown, $t_{0}=46000 \mathrm{~h}\left(1.65 \times 10^{8} \mathrm{~s}\right)$ and $n=1 / 2$. From the experimental points represented in figures $1(a)$ and $(b)$ (master curves of Spec.1) the identified values of the model's parameters are $\beta=1$ (like in the Cole and Davidson model), $\alpha$ $=0.236, \tau=2 \times 10^{-9} \mathrm{~s}, E^{\mathrm{r}}\left(t_{\mathrm{v}}\right)=1.62,1.91,2.12$ and $2.37 \mathrm{MPa}$, $E^{\mathrm{i}}\left(t_{\mathrm{v}}\right)=28.2,34,38.2$ and $43.1 \mathrm{MPa}$ for $t_{\mathrm{v}}(\mathrm{h})=0,11000$, $56000 \mathrm{~h}$ and $\infty$, respectively (Spec.1). The corresponding curves are drawn in figures $1(a)$ and $(b)$. Hence, for Spec.1,

\begin{tabular}{|c|c|c|c|c|}
\hline \multicolumn{5}{|c|}{$\begin{array}{l}\text { Model: } n=1 / 2, t_{0}=1.65 \times 10^{8} \mathrm{~s}, \beta=1, \alpha=0.236 \\
\tau=2 \times 10^{-9} \mathrm{~s}, 10^{-2}<f<10^{5} \mathrm{~Hz}\end{array}$} \\
\hline \multicolumn{4}{|c|}{$\begin{array}{ll} & E^{\mathrm{r}}(0) \\
\text { Curing conditions } & (\mathrm{MPa})\end{array}$} & $\begin{array}{l}E^{\mathrm{i}}(\infty) \\
(\mathrm{MPa})\end{array}$ \\
\hline & \multicolumn{3}{|c|}{ at $65^{\circ} \mathrm{C}$} & 43.1 \\
\hline $\begin{array}{l}\text { Spec. } 2: 10 \mathrm{~h} \\
\text { at } 65^{\circ} \mathrm{C}\end{array}$ & 1.9 & 2.6 & 28.2 & 43.1 \\
\hline $\begin{array}{l}\text { Spec. } 3: 30 \mathrm{~min} \\
\text { at } 180^{\circ} \mathrm{C}\end{array}$ & 2.6 & 2.6 & 43.1 & 43.1 \\
\hline
\end{tabular}
$E^{\mathrm{r}}(0)=1.62 \mathrm{MPa}, E^{\mathrm{r}}(\infty)=2.37 \mathrm{MPa}$ and $E^{\mathrm{i}}(0)=28.2 \mathrm{MPa}$, $E^{\mathrm{i}}(\infty)=43.1 \mathrm{MPa}$. Note that $E^{\mathrm{r}}(\infty) / E^{\mathrm{r}}(0) \sim 1.46$ and $E^{\mathrm{i}}(\infty) /$ $E^{\mathrm{i}}(0) \sim 1.53$ which is close to the values calculated from the kinetics at 0.01 and $80 \mathrm{~Hz}$ in figure 3: 1.49 and 1.55 , respectively. As shown in figures $2(a)$ and $(b)$, the curing conditions
Table 1. Relaxed and instantaneous moduli at zero and infinite aging times.

of Spec. 3 are sufficient to assure constant mechanical properties, i.e. no perceptible evolution of the moduli between 240 and $6000 \mathrm{~h}$, and the nano-indentation results $(f \sim 0.02 \mathrm{~Hz})$ at $t_{\mathrm{v}}=62000 \mathrm{~h}$ is close to those at $0.01 \mathrm{~Hz}$ for shorter aging time (figures 2(a) and $(b)$ ). Moreover, it is interesting to observe that the calculated values from the model of the storage modulus at 1 and $80 \mathrm{~Hz}$ for an infinite aging time, $E^{\prime}(\infty, 1 \mathrm{~Hz})=$ $2.88 \mathrm{MPa}$ and $E^{\prime}(\infty, 80 \mathrm{~Hz})=3.86 \mathrm{MPa}$ approximately correspond to those of Spec.3 for the same frequencies, 3.04 and $3.95 \mathrm{MPa}$, respectively. Hence, as shown in figures 2(a) and (b) for very long aging times, the mechanical properties of Spec. 1 and Spec. 2 tends to those of Spec.3. From these observations, it can be concluded that the instantaneous moduli at very long aging time for the three studied samples are sensibly identical and that only the relaxed moduli are very dependent on the curing conditions. For the three studied specimens the proposed values for $E^{\mathrm{r}}(0), E^{\mathrm{r}}(\infty), E^{\mathrm{i}}(0)$ and $E^{\mathrm{i}}(\infty)$ are reported in table 1.

In the previous model (equations $(3 c)-(3 \mathrm{~g})$ ) it has been assumed that $E^{\prime}\left(t_{\mathrm{v}}, \omega\right)$ and $E^{\prime \prime}\left(t_{\mathrm{v}}, \omega\right)$ follow the same aging kinetic, thus the tangent of the phase lag, $\tan (\delta)=$ $E^{\prime \prime}\left(t_{\mathrm{v}}, \omega\right) / E^{\prime}\left(t_{\mathrm{v}}, \omega\right)$, should be independent of the aging kinetic and thus of the curing conditions. This hypothesis is fairly well validated in figure 4 where $\tan (\delta)$ for the three studied specimens and the set of experimental conditions describe the same master curve as a function of the frequencies. Note that 


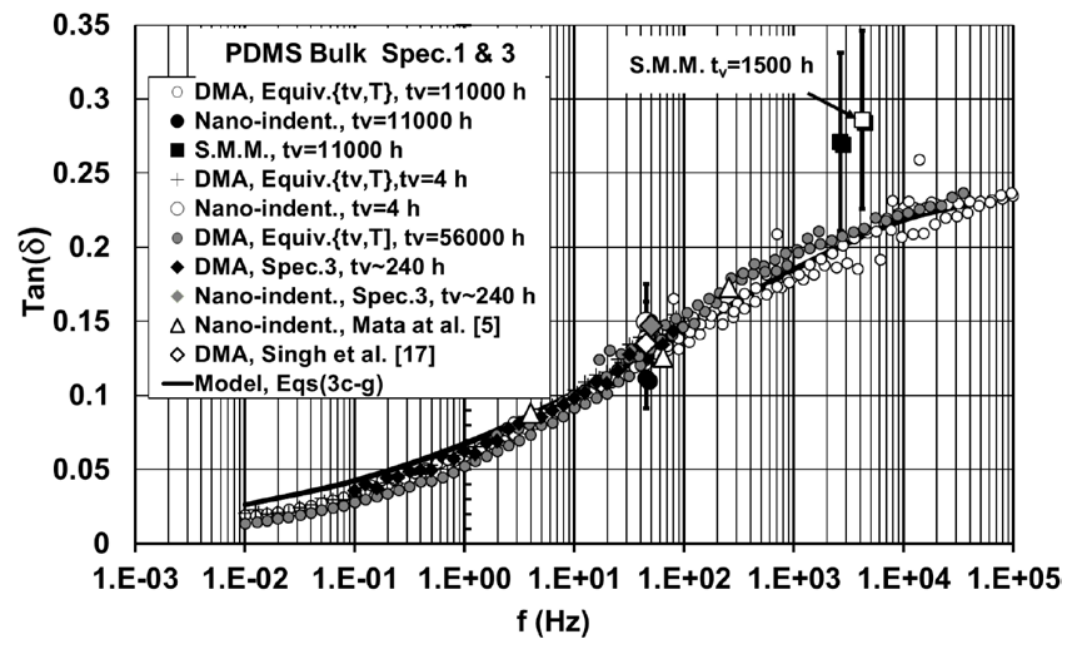

Figure 4. Tangent of the phase lag (Spec.1, Spec.2 and Spec.3) as a function of the frequency and the aging time. The results of Mata $e t$ al [5] and Singh et al [17] are also reported for 4, 64, 256 and $45 \mathrm{~Hz}$, respectively. For the legibility of the figure the points of Spec.2 have not been reported but perfectly match the master curve. Model, equations (3c)-(3g).

Table 2. Literature results of relaxed (quasi static tests) modulus as a function of the curing conditions.

\begin{tabular}{|c|c|c|c|}
\hline Authors & $\begin{array}{l}\text { Curing conditions: } \\
\text { 10:1 cross-linker }\end{array}$ & $\begin{array}{l}E^{\mathrm{r}}(0) \\
(\mathrm{MPa})\end{array}$ & $\begin{array}{l}E^{\mathrm{r}}(\infty) \\
(\mathrm{MPa})\end{array}$ \\
\hline \multirow[t]{3}{*}{ du Roure et al [9] } & $4 \mathrm{~h}$ at $65^{\circ} \mathrm{C}$ & 1.5 & - \\
\hline & $12 \mathrm{~h}$ at $65^{\circ} \mathrm{C}$ & 2 & - \\
\hline & $168 \mathrm{~h}$ at $65^{\circ} \mathrm{C}$ & 2.5 & - \\
\hline Mata et al [5] & $30 \min$ at $95^{\circ} \mathrm{C}$ & $\begin{array}{l}1.45 \\
(\text { at } 4 \mathrm{~Hz})\end{array}$ & - \\
\hline Gupta et al [16] & $336 \mathrm{~h}$ at $25^{\circ} \mathrm{C}$ & 1.5 & - \\
\hline \multirow[t]{2}{*}{ Schneider et al [8] } & $15 \min$ at $150^{\circ} \mathrm{C}$ & 1.82 & - \\
\hline & $\begin{array}{l}15 \mathrm{~min} \text { at } 150^{\circ} \mathrm{C}+ \\
4 \mathrm{~h} \text { at } 200^{\circ} \mathrm{C}\end{array}$ & - & 2.6 \\
\hline Khanafer et al [13] & $12 \mathrm{~h}$ at $65^{\circ} \mathrm{C}$ & 2.1 & - \\
\hline \multirow[t]{4}{*}{ Johnston et al [15] } & $48 \mathrm{~h}$ at $25^{\circ} \mathrm{C}$ & 1.32 & - \\
\hline & $48 \mathrm{~min}$ at $100^{\circ} \mathrm{C}$ & 2.05 & - \\
\hline & $23 \mathrm{~min}$ at $150^{\circ} \mathrm{C}$ & 2.59 & - \\
\hline & 18 min at $200^{\circ} \mathrm{C}$ & - & 2.97 \\
\hline Singh et al [17] & $15 \mathrm{~min}$ at $120^{\circ} \mathrm{C}$ & 2.05 & - \\
\hline
\end{tabular}

this conclusion has been established for a given percentage of cross-linker, $10 \%$ recommended by the manufacturer. There are only a few results in the literature to confirm this conclusion. However, the nano-indentation results of Mata et al [5] obtained on a PDMS with $10 \%$ of cross-linker cured during $30 \mathrm{~min}$ at $95^{\circ} \mathrm{C}$ and reported in figure 4 for 4,64 and $256 \mathrm{~Hz}$, perfectly match the master curve and thus accredit the previous conclusion. This is equally true for the DMA result at $45 \mathrm{~Hz}$ reported by Singh et al [17] for a PDMS (10:1) cured for $15 \mathrm{~min}$ at $120^{\circ} \mathrm{C}$ (figure 4 ).

\section{Discussion with regard to the literature}

For the PDMS with $10 \%$ cross-linker, contrary to the dynamics tests, many studies have been reported in the literature for quasi-static conditions. The present results (storage relaxed modulus) are compared to those of the literature in table 2 (values) and in figure 5. Hence, in this figure the storage modulus $E^{\prime}$ for quasi-static conditions is plotted as a function of the curing time $t_{\mathrm{c}}$ and for different curing temperatures $T_{\mathrm{c}}$. It is thus shown that the values obtained for Spec. 1 and Spec. 2 at $T_{\mathrm{c}}=65^{\circ} \mathrm{C}$ are in fairly good agreement with those in the literature. Moreover, for this curing temperature and, as previously mentioned, for very long aging times $t_{\mathrm{v}}$, for long curing time $\left(t_{\mathrm{c}}>1000 \mathrm{~h}\right) E^{\prime}$ tends to $E^{\mathrm{r}}(\infty)$ which is in the range $2.6-2.97 \mathrm{MPa}[8,15]$, values corresponding to high curing temperature $\left(150^{\circ} \mathrm{C}<T_{\mathrm{c}}<200^{\circ} \mathrm{C}\right)$ for relatively short curing times $\left(t_{\mathrm{c}}<1 \mathrm{~h}\right)$. The value obtained for Spec. 3 is $2.6 \mathrm{MPa}$ (figure $1(a)$ ). Note that above $200^{\circ} \mathrm{C}$, as mentioned by Liu et al [12], thermal decomposition of PDMS begins.

Note that for a given curing temperature $T_{\mathrm{c}}$ and as a function of the curing time $t_{\mathrm{c}}$, a kinetic close to that written in equation $(3 g)$ could be applied to $E^{\mathrm{r}}(0)$. So, this relation could be rearranged as:

$$
\begin{gathered}
E^{\mathrm{r}}\left(t_{\mathrm{v}}, t_{\mathrm{c}}\right)=E^{\mathrm{r}}\left(0, t_{\mathrm{c}}\right)+\left(E^{\mathrm{r}}(\infty, \infty)-E^{\mathrm{r}}\left(0, t_{\mathrm{c}}\right)\right) \\
{\left[1-\exp -\left(\frac{t_{\mathrm{v}}}{t_{0}}\right)^{n}\right] \text { with }} \\
E^{\mathrm{r}}\left(0, t_{\mathrm{c}}\right)=E^{\mathrm{r}}(0,0)+\left(E^{\mathrm{r}}(\infty, \infty)-E^{\mathrm{r}}(0,0)\right) \\
{\left[1-\exp -\left(\frac{t_{\mathrm{c}}}{t_{0 \mathrm{c}}}\right)^{n}\right] \quad \text { and where } t_{0 \mathrm{c}}=A \exp \left(\frac{\Delta H}{n \mathrm{k} T_{\mathrm{c}}}\right)}
\end{gathered}
$$

is a thermally activated parameter. $k$ is the Boltzmann's constant and $\Delta H$ the activation energy. For $T_{\mathrm{c}}=65^{\circ} \mathrm{C}$ the parameters of the relation (4) have been identified on the experimental points (figure 5, the literature and this study). We keep $n=1 / 2$ as for the aging time kinetic. Hence, $E^{\mathrm{r}}(0,0)=$ $1.1 \mathrm{MPa}, E^{\mathrm{r}}(\infty, \infty)=2.7 \mathrm{MPa}$ and $t_{0 \mathrm{c}}=7.2 \times 10^{4} \mathrm{~s}(20 \mathrm{~h})$. Then, $t_{0 \mathrm{c}}$ has been calculated to adjust the kinetics at 25,100 and $160{ }^{\circ} \mathrm{C}$ (figure 5 ): $t_{0 \mathrm{c}}=1.1 \times 10^{7}, 3.6 \times 10^{3}$ and $180 \mathrm{~s}$, respectively. From the four $t_{0 \mathrm{c}}$ values $\left(\ln \left(t_{0 \mathrm{c}}\right)=f\left(1 / T_{\mathrm{c}}\right)\right.$ an activation energy $\Delta \mathrm{H}=0.4 \pm 0.1 \mathrm{eV}$ has been calculated. This value is somewhat uncertain but is in fairly good agreement with that of the $\beta$ transition, $\Delta H_{\beta} \sim 0.5 \mathrm{eV}$, which it often turns out to be 


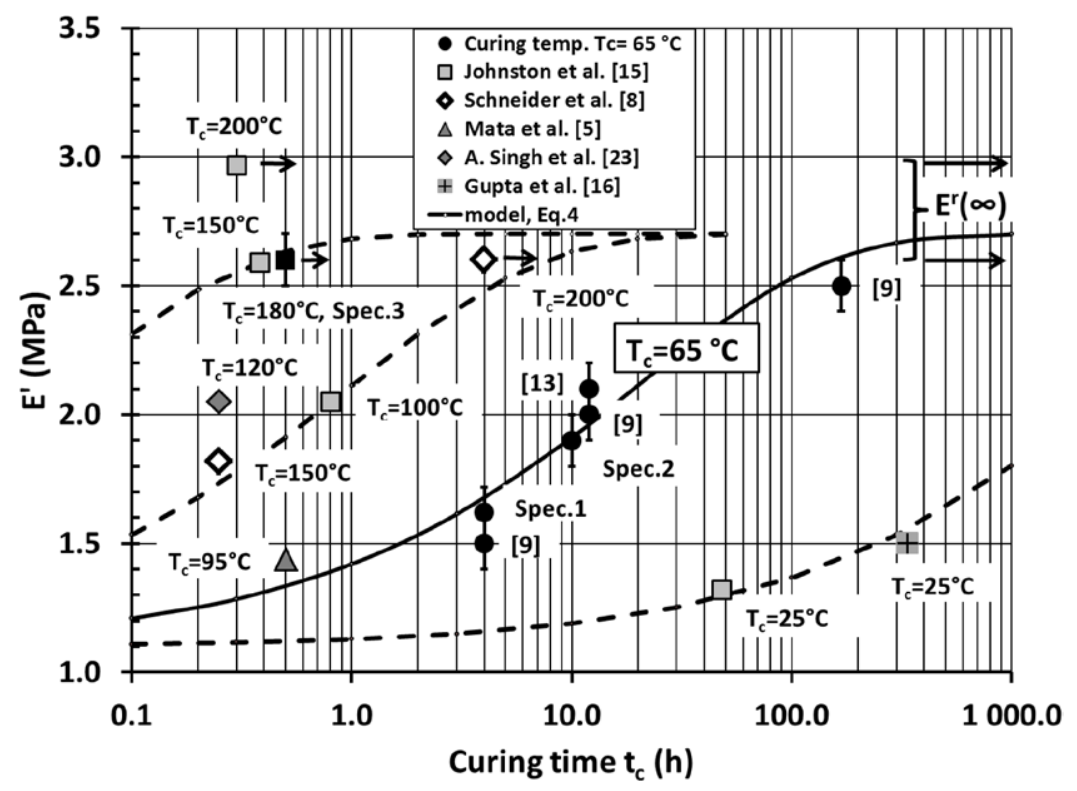

Figure 5. Evolution of the quasi-static storage modulus as a function of the curing time for different curing temperatures. Present study and literature. Model, equation (4).

in activation barriers of deformation, diffusion, physical aging and solid phase reactions in PDMS material [25].

As a conclusion, the value of the relaxed modulus for an uncured PDMS is about $E^{\mathrm{r}}(0,0)=1.1 \mathrm{MPa}$ and is $E^{\mathrm{r}}(\infty, \infty)=$ $2.7 \pm 0.1 \mathrm{MPa}(\times 2.5)$ for a fully tempered material. From a physical point of view, Sylgard 184 is composed of a monomer and hardener combined at a ratio of 10:1 and for an incomplete curing process there is always an excess of hardener. During the curing procedure and the aging at room temperature the excess hardener is further cross-linked with additional fillers from the monomer and thus the mechanical properties increase. Of course, and as shown in figure 5, this cross-linking is a thermally activated phenomenon.

In the fluidic dynamic MEMS applications (fluidic circuits, valves, pumps etc) the frequency range is often lower than $20 \mathrm{~Hz}$ and consequently the precise knowledge of the dynamic mechanical properties between the quasi-static conditions and $20 \mathrm{~Hz}$ is required $\left(10^{-2}<f<20 \mathrm{~Hz}\right)$. In this range, as previously reported, the storage modulus increases by a ratio of 1.3 from the static conditions (figure $1(a)$ ) and the tangent of the phase lag by a ratio of about $4.6\left(2.4 \times 10^{-2}\right.$ to $1.1 \times 10^{-1}$, figure 4$)$. Hence, for these kinds of applications the knowledge of the dynamic mechanical properties of this material is suitable. For dynamic sensors applications (acceleration sensors, capacitive accelerometers with PDMS spring, dielectric elastomer actuators, energy harvesting etc) [26-28], the frequency range is higher than the previous one, typically between $100 \mathrm{~Hz}$ and some $\mathrm{kHz}$ and, as previously shown in this paper (figures $1(a)$, (b) and 4), the mechanical properties greatly evolve and are definitively required to accurately design such active sensors or actuators. Moreover, an interesting result of this study for the design is the independence of the tangent of the phase lag to the curing conditions.

Note that numerous applications have been performed with $10 \%$ curing agent, as recommended by the manufacturer, but for certain dynamic PDMS applications [1-7, 26-28] it could be interesting to study this further, as for quasi-static conditions [13], the dynamic modulus changes with different monomer-hardener ratios to produce a softening for easier activation.

\section{Conclusion}

The dynamic mechanical characterization of PDMS over a large range of frequencies and long aging times at room temperature has been reported, thanks to three experimental techniques. The storage and the loss moduli greatly increase with the frequency $\left(0.01<f<10^{5} \mathrm{~Hz}\right)$ and moderately with the aging time. A simple model which takes these two behaviors into account has been presented and identified. Values of relaxed and instantaneous moduli $E^{\mathrm{r}}\left(t_{\mathrm{v}}\right), E^{\mathrm{i}}\left(t_{\mathrm{v}}\right)$ at $t_{\mathrm{v}}=0$ and $\infty$ are proposed. The calculated values of the relaxed modulus are in good agreement with those reported in the literature. Only the relaxed modulus seems to depend on the curing conditions and moreover that the tangent of the phase lag is shown to be independent of the aging time and thus of the curing process.

Through our investigation into the effect of aging at ambient temperature on the dynamic mechanical properties of Sylgard 184 PDMS we hope to provide quantitative information for researchers designing active sensors and actuators, such as micro-valves, micro-pumps, accelerometers etc, employing this elastomer cured under certain conditions $\left(t_{\mathrm{c}}\right.$ at $\left.T_{\mathrm{c}}\right)$ as a structural material.

\section{References}

[1] Lötters J C, Olthuis W, Veltink P H and Bergueld P 1997 The mechanical properties of the rubber elastic polymer polydimethylsiloxane for sensor applications J. Micromech. Microeng. 7 145-7 
[2] Unger M A, Chou H P, Thorsen T, Scherer A and Quake S R 2000 Monolithic micro-fabricated valves and pumps by multilayer soft lithography Science 288 113-6

[3] McDonald J C and Whitesides G M 2002

Polydimethylsiloxane as a material for fabricating microfluidic devices Acc. Chem. Res. 35 491-9

[4] Khan Malek C, Thuillier G and Blind P 2004 Hybrid replication development for construction of polymeric devices Microsyst. Technol. 10 711-5

[5] Mata A, Fleischman A J and Roy S 2005 Characterization of polydimethylsiloxane properties for biomedical micro/ nanosystems Biomed. Microdevices 7 281-93

[6] Chen J, Wang W, Fang J and Varahramyan K 2004 Variablefocusing microlens with microfluidic chip J. Micromech. Microeng. 14 675-80

[7] Werber A and Zappe H 2006 Thermo-pneumatically actuated, membrane-based micro-mirror devices J. Micromech. Microeng. 16 2524-31

[8] Schneider F, Fellner T, Wilde J and Wallrabe U 2008 Mechanical properties of silicones for MEMS J. Micromech. Microeng. 18065008

[9] du Roure O, Saez A, Buguin A, Austin R H, Chavrier P, Siberzan P and Ladoux B 2005 Force mapping in epithelial cell migration PNAS 1027 2390-5

[10] Johnston I D, Tracey M C, Davis J B and Tan C K L 2005 Micro throttle pump employing displacement amplification in an elastomeric substrate J. Micromech. Microeng. 15 1831-9

[11] Sollier E, Murray C, Maoddi P and Di Carlo D 2011 Rapid prototyping polymers for microfluidic devices and high pressure injections Lab Chip 11 3752-65

[12] Liu M, Sun J and Chen Q 2009 Influences of heating temperature on mechanical properties of polydimthylsiloxane Sensors Actuators A 151 42-5

[13] Khanafer K, Duprey A, Schlicht M and Berguer R 2009 Effects of strain rate, mixing ratio and stressstrain definition on the mechanical behavior of polydimethylsiloxane (PDMS) material as related to its biological applications Biomed. Microdevices 11 503-8

[14] Kim T K, Kim J K and Jeong O C 2011 Measurement of non linear mechanical properties of PDMS elastomer Microelectron. Eng. 88 1982-5

[15] Johnston I D, Mc Cluskey D K, Tan C K L and Tracey M C 2014 Mechanical characterization of bulk Sylgard 184 for microfluidics and microengineering J. Micromech. Microeng. 24035017
[16] Gupta S, Carrillo F, Li C, Pruitt L and Puttliz C 2007 Adhesive force significantly affect elastic modulus determination of soft polymeric materials in nanoindentation Mater. Lett. $61448-51$

[17] Singh A, Hirsinger L, Delobelle P and Khan Malek C 2014 Rapid prototyping of magnetic valve based on nanocomposite Co/PDMS membrane MicroSyst. Technol. 20 427-36

[18] Dow Corning 2014 Product Information Sylgard 184 Silicone Elastomer FormNo 11-3184B-01

[19] Thuillier G and Khan Malek C 2005 Development of a low cost hybrid Si/PDMS multi-layered pneumatic microvalve Microsyst. Technol. 12 180-5

[20] Oliver W C and Pharr G M 1992 An improved technique for determining hardness and elastic-modulus using load and displacement sensing indentation experiments J. Mater. Res. 7 1564-83

[21] Le Rouzic J, Delobelle P, Vairac P and Cretin B 2009 Comparison of three different scales techniques for the dynamic mechanical characterization of two polymers Eur. Phys. J. Appl. Phys. 4811201

[22] Vairac P and Cretin B 1996 Scanning microdeformation microscopy in reflection mode Appl. Phys. Lett. 68 461-5

[23] Le Rouzic J, Delobelle P, Cretin B, Vairac P and Amiot F 2012 Simultaneous measurement of Young's modulus and Poisson's ratio at microscale with two-modes scanning microdeformation microscopy Mater. Lett. 68 370-3

[24] Havriliak S and Negami S 1967 A complex plane representation of dielectric and mechanical relaxation processes in some polymers Polymer 8 161-210

[25] Dusek K and Joany J F 2010 Polymer Characterization: Rheology, Laser Interferometry, Electrooptics (Berlin: Springer) pp 89-139

[26] Carpi F, de Rossi D, Kornbluh R and Sommer-Larsen P 2008 Dielectric Elastomers and Electromechanical Transducers; Fundamentals, Materials, Devices, Models and Applications of an Emerging Electroactive Polymer Technology (Amsterdam: Elsevier)

[27] Lötters J C, Olthuis W, Veltink P H and Bergveld P 1996 Polydimethylsiloxane as an elastic material applied in a capacitive accelerometer J. Micromech. Microeng. 6 52-4

[28] Molberg M, Leterrier Y, Plummer C J G, Walder C, Löwe C, Opris D M, Nüesch F A, Bauer S and Manson J E 2009 Frequency dependent dielectric and mechanical behavior of elastomers for actuator applications J. Appl. Phys. 106054112 


\section{QUERIES}

\section{Page 1}

AQ1

Please be aware that the colour figures in this article will only appear in colour in the web version. If you require colour in the printed journal and have not previously arranged it, please contact the Production Editor now.

AQ2

The definitions of 'MOEMS' and 'MEMS' have been added in this sentence. Please confirm they are correct.

Page 2

AQ3

Please check the usage of the term [2 10-2 s-1 in this context.]

Page 3

AQ4

Please check the sense of the sentence "an Avrami's kinetic have been chosen".

Page 7

AQ5

Please check the details for any journal references that do not have a link as they may contain some incorrect information. 